\title{
Relationship of air temperature to various chemical, haematological, and haemostatic variables
}

\author{
G. M. BULL ${ }^{1},{ }^{*}$ MILICA BROZOVIC ${ }^{2}$, R. CHAKRABARTI ${ }^{2}, T$. W. MEADE ${ }^{2}$, \\ JOAN MORTON', W. R. S. NORTH ${ }^{2}$, AND YVONNE STIRLING ${ }^{2}$ \\ From the ${ }^{1}$ Clinical Research Centre and the ${ }^{2} M R C$-DHSS Epidemiology and Medical Care Unit, \\ Northwick Park Hospital, Watford Road, Harrow, Middlesex, HAl 3UJ, UK
}

SUMMARY Results for biochemical and haematological variables have been correlated with data on atmospheric temperature in order to identfy possible mechanisms through which low environmental temperature may increase mortality from myocardial infarction and cerebrovascular disease. With the exception of cholesterol, there were no associations in the case of several clinical chemistry variables, or of haemoglobin and related indices. With varying degrees of consistency among the sex and age groups studied, temperature was positively correlated with factor VII, antithrombin III, and cholesterol, and negatively correlated with fibrinolytic activity. The correlations were all low but may offer some clues to mechanisms whereby air temperature influences ischaemic heart and cerebrovascular disease mortality.

In previous publications we reported that there is a negative correlation between atmospheric temperature and the death rates from a number of conditions, in particular, myocardial infarction and cerebrovascular accidents (Bull, 1969; Bull, 1973; Bull and Morton, 1975a, b). This inverse relationship between temperature and death rates was confined to or found to be greatest in older subjects (Bull, 1973; Bull and Morton, 1975a).

In these earlier publications we speculated on a possible causal relationship between temperature and cerebrovascular and ischaemic heart disease. If the relationship between environmental temperature and mortality rates from arterial diseases is one of cause and effect, it is presumably mediated by changes in one or more body systems; these changes might be detectable in groups of people (mostly without clinical arterial disease) for whom biochemical, haematological, and other data can be related to environmental temperature. We have therefore studied the associations between the levels of various blood constituents and atmospheric temperature.

\section{Material}

There are four sources of data.

1 THE CLINICAL CHEMISTRY

DEPARTMENT OF NORTHWICK PARK

HOSPITAL

Clinical chemistry results in this hospital are stored

* Present address: Central Middlesex Hospital, Acton Lane, Middlesex, NW10 7NS

Received for publication 13 March 1978 in an archival file on a computer together with identifying particulars and the date of the sample. The file for 1973 was used to prepare a table of the mean blood levels of 10 blood constituents by days in each sex and in two age groups $(<55$ and $>55$ years). All readings outside the limits of 2 standard deviations (SD) from the quality control mean of the laboratory were rejected before calculation of the daily means. Thus the mean values should approximate to the 'normal' mean values for this hospital's population. In all, data from 103370 individual blood samples were available for analysis, and on most of these five or more blood constituents were analysed.

The number of individual readings making up the daily mean varied, and on certain days, at weekends or on public holidays, none was available. The missing values were filled by inserting the average of the readings straddling the vacant cell.

2 THE SERVICE HAEMATOLOGY

DEPARTMENT OF NORTHWICK PARK

HOSPITAL

As part of the quality control system for this department, a register is kept of the mean and standard deviation of each day's results for the red cell count, haemoglobin concentration, and packed cell volume, and the derived values of mean corpuscular volume and mean corpuscular haemoglobin concentration. Values lying outside 2 SD from the mean are rejected before calculation of the daily means. The figures are therefore comparable with those from the Clinical Chemistry Department described above but are not subdivided by sex and age. They were treated in the same way as the clinical 
chemistry results except that two years' data were used instead of one.

\section{INDUSTRIAL POPULATIONS AND VOLUNTEERS}

Data on several haemostatic variables have been collected in the course of a prospective study of ischaemic heart disease in a number of working populations in north-west London (Meade et al., 1977). The findings in this report are based on 1149 white men (911 aged 18-54; 238 aged 55-64) and 638 women (527 aged 18-54, and 111 aged 55-59) all working on the day shift. All blood samples were taken between 0700 and 1100 hours. The haemostatic variables considered are factors V, VII, and VIII, fibrinogen, antithrombin III (biological activity), fibrinolytic activity, platelet count, and platelet adhesiveness. Full details of methods, etc, are given elsewhere (Meade et al., 1977). Values for these variables in the industrial groups are available on only one occasion for each individual.

The haemostatic tests have also been carried out on several occasions over a period of about four years in 17 male and 21 female volunteers whose mean ages were 35 and 28 years respectively. There were 222 observations in the men and 188 in the women.

\section{TEMPERATURE DATA}

The daily minimum temperatures were obtained from the London Weather Centre and are those prevailing there.

\section{Statistical methods}

For the clinical chemistry and haematology data the statistical method used was to compare the difference between the mean readings on two successive days with the temperature difference between these two days using the correlation coefficient to test for an association. Then because of the possibility that a temperature change of longer than one day's duration might be relevant, the days were grouped in pairs, the mean values for the two days being correlated with the change in temperature over the two days. This procedure was repeated for groups of 3, $4 \ldots$ up to 10 days (see Bull and Morton, 1975a).

The calculations were then repeated, allowing for the possibility that there may be a lag of a number of days before the temperature effect is seen, so that each reading was associated not with the temperature on the day the blood was taken but with the temperature on the day before, or $2,3 \ldots$ up to 10 days before ('phase shift' days), and similarly with groups of days.

For the industrial populations, no groupings of days was possible as blood samples were not taken on successive days. Instead, individual readings were correlated with temperature on the day of sampling or on 1,2, 3 to 9 days previously ('phase shift' days).

For the volunteers, the data were examined for correlations within individuals, these estimates being pooled to give the best overall estimate of withinperson correlation with temperature. This procedure was also carried out for 1,2,3 to 9 'phase shift' days.

\section{Results}

\section{CLINICAL CHEMISTRY RESULTS}

The levels of the following blood constituents were correlated with temperature:

Aspartate transaminase Uric acid

Urea

Sodium

Cholesterol

Potassium

Thyroxin

Alkaline phosphatase

Calcium

Phosphorus.

Table 1 is a small part of the complete table of results included to illustrate the organisation of the data. The figures $0,1,2$, etc. are the 'phase

Table 1 Clinical chemistry data: Aspartate transaminase

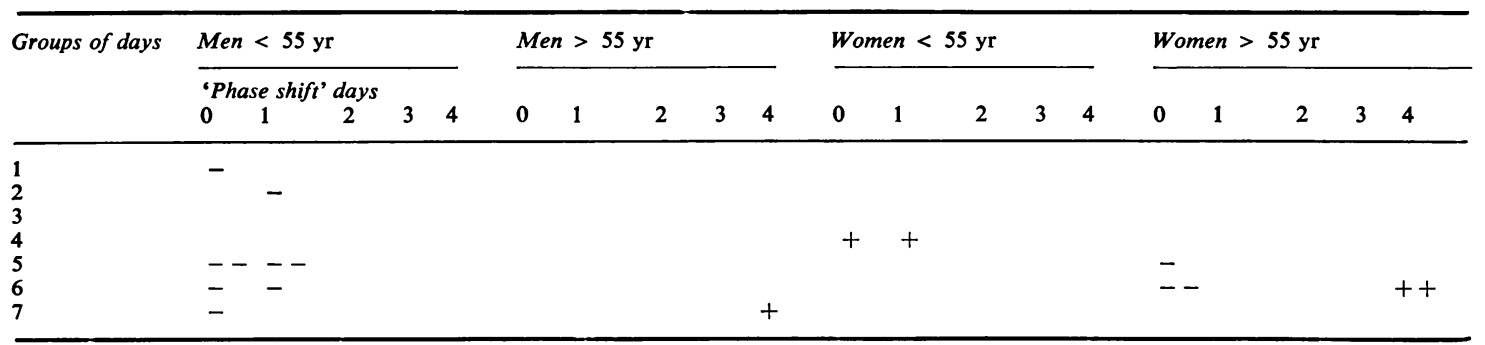

\footnotetext{
- negative correlation at $P<0.05$

- negative correlation at $P<0.01$

+ positive correlation at $P<0.05$

++ positive correlation at $P<0.01$
} 
Table 2 Haematology data: Significance of correlations with temperature without and with 'phase shifts', all ages, both sexes

\begin{tabular}{|c|c|c|c|c|c|c|c|c|c|c|c|c|}
\hline \multirow[t]{2}{*}{$\begin{array}{l}\text { Groups of } \\
\text { days }\end{array}$} & \multicolumn{12}{|c|}{ 'Phase shift' days } \\
\hline & $R B C s$ & $H b$ & $P C V$ & $M C V$ & $\mathrm{MCHC}$ & $R B C s$ & $H b$ & $P C V$ & $M C V$ & $M C H C$ & $R B C S$ & $H b$ \\
\hline
\end{tabular}

\begin{tabular}{l}
\hline 1 \\
2 \\
7 \\
14 \\
28 \\
See Table 1 for explanation of symbols
\end{tabular}

shift' days as defined in Statistical methods.

The 'Groups of days' on the vertical column are as defined in paragraph 2 of Statistical methods. We found no more statistically significant correlations than would be expected by chance, and sometimes they were in different directions (eg, Table 1) for the same determination. The absence of any consistent pattern suggests that there is no significant relationship between temperature and the measurements.

HAEMATOLOGY RESULTS

Table 2 shows the haematology results. For the same reasons given in the case of the clinical chemistry results there appears to be no significant relationship between temperature and the measurements.

INDUSTRIAL POPULATIONS AND

VOLUNTEERS: HAEMOSTATIC RESULTS

The haemostatic data are the only set of variables described here for which there are correlations of a consistency suggesting a true relationship with temperature.

The results shown in Table 3 are those where correlations significant at the $5 \%$ level, or less, are found (i) for all or most of the 'phase shift' day within any of the four age-sex groupings in the industrial groups, as well as for the day of sampling itself, and (ii) for either the men or the women volunteers, or both.

In the case of factors V and VIII, fibronogen, platelet count, and platelet adhesiveness, there was no evidence of any association with temperature in any of the four groups in the industrial populations or in the volunteers. As shown in Table 3, however, there was a consistent and highly significant positive correlation between factor VII and temperature in the men under 55; this association was not, however, seen in any of the other three groups in the industrial population or in the volunteers. In the case of antithrombin III, there were significant positive correlations in the men over 55 and in the women under 55; similar correlations were also consistently found in both the male and female volunteers.

In both groups of men (industrial), there were significant negative correlations between fibrinolytic activity and temperature. In the women, the correlations were also consistently negative, but they

Table 3 Correlations of variables in (a) industrial groups, and (b) volunteers, with temperature, where a consistent pattern emerged within any of the age-sex groupings of $(a)$ or within either sex in $(b)$ : see text

\begin{tabular}{|c|c|c|c|c|c|c|c|c|c|c|c|c|}
\hline \multirow{3}{*}{$\frac{\operatorname{Age}(y r)}{\operatorname{Day} \dagger}$} & \multicolumn{8}{|l|}{ Male } & \multirow{2}{*}{\multicolumn{4}{|c|}{$\begin{array}{l}\text { Female } \\
<55(N=527)\end{array}$}} \\
\hline & \multicolumn{4}{|c|}{$<55(N=911)$} & \multicolumn{4}{|c|}{$>55(N=238)$} & & & & \\
\hline & 0 & 1 & 2 & 3 & 0 & 1 & 2 & 3 & 0 & 1 & 2 & $\underset{\sim}{*}$ \\
\hline $\begin{array}{l}\text { Factor VII } \\
\text { Antithrombin } \\
\text { III }\end{array}$ & $\begin{array}{l}+0 \cdot 134^{* * *} \\
+0.013\end{array}$ & $\begin{array}{l}+0 \cdot 144 * * * \\
+0.022\end{array}$ & $\begin{array}{l}+0.150^{* * *} \\
+0.026\end{array}$ & $\begin{array}{l}+0.139 * * * \\
+0.031\end{array}$ & $\begin{array}{r}+0.014 \\
+0.118\end{array}$ & $\begin{array}{l}-0.005 \\
+0.148^{*}\end{array}$ & $\begin{array}{l}+0.007 \\
+0.170^{* *}\end{array}$ & $\begin{array}{l}+0.035 \\
+0.148^{*}\end{array}$ & $\begin{array}{l}+0.052 \\
+0.090^{*}\end{array}$ & $\begin{array}{l}+0.046 \\
+0.114^{*}\end{array}$ & $\begin{array}{l}+0.053 \\
+0.091^{*}\end{array}$ & $\begin{array}{l}+0.0 \overline{6} \\
+0.094^{*}\end{array}$ \\
\hline
\end{tabular}


3

\begin{tabular}{|c|c|c|c|c|c|c|c|c|c|c|c|}
\hline$V$ & $M C H C$ & $R B C s$ & $H b$ & $P C V$ & $M C V$ & $M C H C$ & $R B C s$ & $\mathrm{Hb}$ & $P C V$ & $M C V$ & $M C H C$ \\
\hline & & +1 & $-\overline{-}$ & $+t$ & $+t$ & ++ & & - & & & \\
\hline
\end{tabular}

were very low and certainly did not reach a conventional level of significance.

Finally, cholesterol was positively and significantly associated with temperature in the men under 55.

\section{Discussion}

The main purpose of this report is to describe any associations between ambient temperature and a range of chemical, haematological, and haemostatic variables. Significant associations might provide a lead to possible ways in which temperature changes could result in alterations in death rates.

Neither the routine clinical chemistry nor the routine haematology data showed any consistent associations of any of the variables studied with ambient temperature, and it was only some of the haemostatic variables and blood cholesterol levels in the industrial and volunteer populations which showed such a relationship. The haemostatic variables were factor VII, antithrombin III, and fibrinolytic activity (see Table 3 ).

In seeking possible explanations for an association between the levels of variables and temperature, it is first necessary to consider whether there may be technical reasons such as an effect of temperature on the laboratory methods involved. Temperature is recorded daily in the laboratory carrying out the haemostatic tests, and there is no evidence that the factor VII and antithrombin III associations were in fact due to influences of temperature on the assay techniques used. In the case of fibrinolytic activity, the test tube containing blood and reagents is kept in an insulated box containing ice until it is put into a water bath at $37^{\circ} \mathrm{C}$ so that here also there is no reason to believe that the observed association is due to a temperature effect on the technique used. There is also no reason to suppose that laboratory temperature influences cholesterol determinations.

A second possibility is that the observed associations are actually due to a seasonal rather than a temperature effect. Further analyses were therefore performed on the haemostatic variables, taking season, as well as temperature, into account. Perhaps partly because of the considerable variability in tests of haemostatic function (Meade et al., 1977) no very clear picture emerged, although in the case of factor VII there was some evidence of a seasonal as well as a temperature effect, levels tending to be higher in the summer than in the winter.

\begin{tabular}{|c|c|c|c|c|c|c|c|c|c|c|c|}
\hline & & & & \multicolumn{8}{|l|}{ Volunteers } \\
\hline & & & & \multicolumn{4}{|l|}{ Male } & \multicolumn{4}{|l|}{ Female } \\
\hline \multicolumn{4}{|c|}{$>55(N=111)$} & \multicolumn{4}{|c|}{35 (mean) $(N=17: 222$ observations $)$} & \multicolumn{4}{|c|}{$28($ mean $)(N=21 ; 188$ observations $)$} \\
\hline 0 & 1 & 2 & 3 & 0 & 1 & 2 & 3 & 0 & 1 & 2 & 3 \\
\hline $\begin{array}{r}-0.120 \\
+0.062\end{array}$ & $\begin{array}{l}-0 \cdot 199^{*} \\
+0.048\end{array}$ & $\begin{array}{r}-0.153 \\
+0.063\end{array}$ & $\begin{array}{r}-0.077 \\
+0.036\end{array}$ & $\begin{array}{l}+0.068 \\
+0.166^{*}\end{array}$ & $\begin{array}{l}+0.087 \\
+0 \cdot 191 * *\end{array}$ & $\begin{array}{l}+0.034 \\
+0.180^{* *}\end{array}$ & $\begin{array}{l}+0.041 \\
+0.184^{* *}\end{array}$ & $\begin{array}{l}+0.074 \\
+0.156^{*}\end{array}$ & $\begin{array}{l}+0.057 \\
+0.169^{*}\end{array}$ & $\begin{array}{r}-0.011 \\
+0.110\end{array}$ & $\begin{array}{l}+0.006 \\
+0.154^{*}\end{array}$ \\
\hline-0.063 & -0.084 & -0.099 & -0.066 & -0.012 & -0.055 & -0.044 & -0.088 & +0.040 & -0.036 & -0.020 & -0.046 \\
\hline$-0 \cdot 139$ & -0.126 & $-0 \cdot 142$ & -0.170 & +0.046 & +0.050 & +0.037 & +0.098 & +0.014 & +0.054 & +0.003 & +0.030 \\
\hline
\end{tabular}


No great weight can be placed on the fact that there is substantial agreement between the values for the correlation coefficients on the day of sampling and on previous days because of the high degree of serial correlation of temperature. However, the data are presented because in earlier studies the introduction of a 'phase shift' between deaths and temperatures proved unexpectedly sensitive (Bull and Morton, 1975b).

The significant positive correlation between cholesterol levels and temperature seen in young men in the industrial group was not seen in the clinical chemistry data. However, changes in cholesterol levels are unlikely to be important in the short term in precipitating events which might lead to myocardial or cerebral infarction, or indeed death from other causes, although they may be important in the long term by affecting the degree of atheroma.

The biological interpretation to be placed on the findings for the haemostatic variables, if these are real and not artefactual, is unclear and, at this stage, entirely speculative.

The most interesting results relate to antithrombin III and fibrinolytic activity. The former is positively correlated with temperature in all groups of subjects (see Table 3) and significantly so in the older men, younger women, and both male and female volunteers. This relationship is such as would tend to prevent thrombosis at higher temperatures and is consistent with the negative relationship between temperature and death rates from myocardial infarction and strokes.

The finding of an inverse association between temperature and fibrinolytic activity, that is, better fibrinolytic activity at lower temperatures, seems paradoxical. However, there are indications (Meade et al., 1977) that, in some circumstances favouring thrombogenesis (for example, use of oral contraceptives), fibrinolytic activity actually increases, perhaps as a protective mechanism. Thus it might be that a rise in fibrinolytic activity in cold weather counters other changes which make a thrombotic event more likely. Bedrak et al. (1964) found an increase in fibrinolytic activity in young men exposed to environmental heat stress, but the temperatures involved were higher than the range considered here. Possibly stress of both heat and cold, if sufficiently extreme, increases fibrinolytic activity.

While consistent and statistically significant, the correlations described are all low. Particular caution is needed in interpreting results based on large numbers, when even a low correlation may nevertheless be highly significant. This caveat applies to the industrial groups and especially to the groups under 55 years of age. The numbers of volunteers are much smaller. It is likely that the actual correlations rather underestimate the true strength of the associations, but in spite of this and other difficulties of interpretation, it is possible that the observed correlations offer some clues to the mechanisms whereby air temperature influences ischaemic heart and cerebrovascular disease mortality.

\section{References}

Bedrak, E., Beer, G., and Furman, K. I. (1964). Fibrinolytic activity and muscular exercise in heat. Journal of Applied Physiology, 19, 469-471.

Bull, G. M. (1969). A comparative study of myocardial infarction and cerebral vascular accidents. Gerontologia Clinica, 11, 193-205.

Bull, G. M. (1973). Meteorological correlates with myocardial and cerebral infarction and respiratory disease. British Journal of Preventive and Social Medicine, 27, 108-113.

Bull, G. M. and Morton, J. (1975a). Seasonal and short-term relationships of temperature with deaths from myocardial and cerebral infarction. Age and Ageing, 4, 19-31.

Bull, G. M. and Morton, J. (1975b). Relationships of temperature with death rates from all causes and from certain respiratory and arteriosclerotic diseases in different age groups. Age and Ageing, 4, 232-246.

Meade, T. W., North, W. R. S., Chakrabarti, R., Haines, A. P., and Stirling, Y. (1977). Populationbased distributions of haemostatic variables. British Medical Bulletin, 33, 283-288.

Requests for reprints to: Dr T. W. Meade, Epidemiology and Medical Care Unit, Medical Research Council, Northwick Park Hospital, Watford Road, Harrow, Middlesex HA1 SUJ. 